\title{
Current status and developments of German curriculum-based residency training programmes in radiation oncology
}

Marcel Büttner ${ }^{1,2}$, Nils Cordes $3,4,5,6,7,8,9$, Tobias Gauer $^{10}$, Daniel Habermehl ${ }^{11}$, Gunther Klautke ${ }^{12}$, Oliver Micke ${ }^{13}$, Matthias Mäurer ${ }^{14}$, Jan Sokoll ${ }^{15}$, Esther Gera Cornelia Troost ${ }^{3,4,5,6,7,8,9}$, Hans Christiansen ${ }^{16^{*}+}$ and Maximilian Niyazi ${ }^{1,2+}$

\begin{abstract}
Purpose: The current status of German residency training in the field of radiation oncology is provided and compared to programmes in other countries. In particular, we present the DEGRO-Academy within the international context.

Methods: Certified courses from 2018 and 2019 were systematically assigned to the DEGRO-Curriculum, retrospectively for 2018 and prospectively for 2019. In addition, questionnaires of course evaluations were provided, answered by course participants and collected centrally.

Results: Our data reveal a clear increase in curriculum coverage by certified courses from 57.6\% in 2018 to $77.5 \%$ in 2019. The analyses enable potential improvements in German curriculum-based education. Specific topics of the DEGRO-Curriculum are still underrepresented, while others decreased in representation between 2018 and 2019. It was found that several topics in the DEGRO-Curriculum require more attention because of a low DEGRO-curriculum coverage. Evaluation results of certified courses improved significantly with a median grade of 1.62 in 2018 to 1.47 in $2019(p=0.0319)$.

Conclusion: The increase of curriculum coverage and the simultaneous improvement of course evaluations are promising with respect to educational standards in Germany. Additionally, the early integration of radiation oncology into medical education is a prerequisite for resident training because of rising demands on quality control and increasing patient numbers. This intensified focus is a requirement for continued high standards and quality of curriculum-based education in radiation oncology both in Germany and other countries.
\end{abstract}

Keywords: Radiotherapy, Radiation oncology, Curriculum, Training, Evaluation, DEGRO

\section{Introduction}

The Academy of the German Society for Radiation Oncology (DEGRO-Academy) was founded in 2004. The principle tenant of the DEGRO-Academy is Continuous

\footnotetext{
*Correspondence: christiansen.hans@mh-hannover.de

†Hans Christiansen and Maximilian Niyazi: Shared senior authorship

${ }^{16}$ Department of Radiation Oncology, Hannover Medical School, 30625 Hannover, Germany

Full list of author information is available at the end of the article
}

Medical Education (CME), implemented through the standardisation of medical specialist training in the field of radiation oncology [1].

The aim of the DEGRO-Academy is the achievement of a homogeneous specialist training across Germany, thus ensuring adequate patient care on a national scale. The need for an improvement of both organisation in specialist training and quality, as well as comparability on a national scale was shown by Semrau et al. [2]. In the original author(s) and the source, provide a link to the Creative Commons licence, and indicate if changes were made. The images or other third party material in this article are included in the article's Creative Commons licence, unless indicated otherwise in a credit line to the material. If material is not included in the article's Creative Commons licence and your intended use is not permitted by statutory regulation or exceeds the permitted use, you will need to obtain permission directly from the copyright holder. To view a copy of this licence, visit http://creativecommons.org/licenses/by/4.0/. The Creative Commons Public Domain Dedication waiver (http://creativeco mmons.org/publicdomain/zero/1.0/) applies to the data made available in this article, unless otherwise stated in a credit line to the data. 
subject area of ionizing radiation their training courses have already benefitted from such standardisation [3].

The DEGRO-Academy certifies educational courses that fulfil the high organisational and qualitative requirements of the society. Additionally, the DEGROAcademy introduced the curriculum required to become a resident in radiation oncology (DEGROCurriculum). This curriculum was designed and approved by a board of German radiation oncology experts [4].

Prior to the introduction of a national curriculum by the DEGRO-Academy, residents in radiation oncology were only subject to the specialty training regulations of the respective state chamber of physicians ("Landesärztekammer") (i.e. Baden-Württemberg [5] and Bavaria [6]) which are now supplemented by the DEGRO-Curriculum.

A national interdisciplinary survey by the German Medical Association ("Bundesärztekammer") proved that radiation oncologists are satisfied with their respective training programmes in radiation oncology between 2009 and 2011 [7, 8]. However, in a recent study conducted by the "young DEGRO" (yDEGRO) in 2018 64\% reported that their residency would benefit from a standardised curriculum $(n=96$, median age of participants 31 years) [9]. The working group yDEGRO, which is comprised of young members of the DEGRO, is not only involved in education, but also independent in research, for instance in the field of lung cancer [10].

A second study reported that $47.2 \%$ of supervising physicians in the training of radiation oncology residents reported large difficulties in finding candidates [11].

The DEGRO-Academy revised its curriculum while building on the results of the study by the yDEGRO. The curriculum complements the current fourth Edition of the "Core Curriculum for Radiation Oncology/ Radiotherapy" by the European Society for Radiotherapy and Oncology (ESTRO) $[9,12,13]$. The aim of the DEGRO-Curriculum is to give residents a comprehensive standardised education without replacing the respective, pre-existing state chamber of physicians guidelines (i.e. Baden-Württemberg [5] and Bavaria [6]). Furthermore, in a previous study conducted by Röper et al. [14], certified refresher courses were analysed and a large interest of the participants in these certified courses was observed. In order to increase quality control, a standardised and comprehensive evaluation of all certified courses is required, thus ensuring a high educational benchmark.

The aim of this report is to determine the quantitative and qualitative development of certified courses after an evaluation of two years from 2018 to 2019, both internally and via an international comparison.

\section{Methods \\ Curriculum}

The data was collected on the basis of the latest curriculum, Version 2018 [4] (see Additional file 1: Curriculum of the DEGRO-Academy). In 2018, the assignment of course to curriculum was performed centrally by the DEGRO-Academy. In 2019 the assignment was performed by either the course director or the DEGROAcademy. The curriculum data were analysed separately for each year.

\section{Evaluation}

The survey was an individual evaluation by the organizers, conducted on site or by mail invitation between March 2018 and December 2019. Questionnaires were provided by the DEGRO-Academy and ensuring their completion was mandatory for all event organisers. After finalisation of the questionnaires by the participants these were collected centrally. The questionnaire consisted of six items assessing didactic quality (teaching quality), personal growth of knowledge (knowledge improvement) relevance in the clinical setting (implication in everyday's practice), clarity of defined learning objectives (clarity of subject material) and a total evaluation (overall score) of the course (Fig. 1). Additional questions pertained to the relevance of the course to current research and the professional backgrounds of the participants. Answers were rated on a nominal scale from 1 (best) to 4 (worst).

\section{Statistics}

The raw data of assignment of course to curriculum and evaluation sheets were collected and stored in the online data base ForMES (Version 2.210, ForMES Service $\mathrm{GmbH}$, Fehmarn, Schleswig-Holstein, Germany). For further analysis we used GraphPad Prism (Version 8, GraphPad Software, San Diego, CA, USA) and Microsoft Excel (Mac Version 16.40, Microsoft, Redmond, WA, USA). Unless otherwise indicated, percentages were rounded off to the nearest integer.

\section{Results}

\section{Curriculum}

In 2018, certified courses achieved an overall coverage of $57.6 \%$ of the curriculum topics and subtopics. The course to curriculum assignment was based on a total of 50 courses. By comparison, the coverage rate in 2019 was $77.5 \%$ for a total of 54 assigned courses (Fig. 2). Thus, a higher percentage of DEGRO-Curriculum topics and subtopics in DEGRO-Academy certified courses were offered to residents in 2019 than in the previous year. 


\section{DEGR $\rightarrow$ \\ A K A D E M I E}

\section{Quality evaluation of the event}

\begin{tabular}{|c|c|c|}
\hline Questions & & Evaluation \\
\hline \multirow{4}{*}{ The learning objectives were clearly defined } & excellent & \\
\hline & good & \\
\hline & satisfactory & \\
\hline & sufficient & \\
\hline \multirow{4}{*}{ Lecture/presentation/didactics } & excellent & \\
\hline & good & \\
\hline & satisfactory & \\
\hline & sufficient & \\
\hline \multirow{4}{*}{ Questions/interaction/discussion } & excellent & \\
\hline & good & \\
\hline & satisfactory & \\
\hline & sufficient & \\
\hline \multirow{4}{*}{ Personal learning success } & excellent & \\
\hline & good & \\
\hline & satisfactory & \\
\hline & sufficient & \\
\hline \multirow{4}{*}{ Relevance for daily work } & excellent & \\
\hline & good & \\
\hline & satisfactory & \\
\hline & sufficient & \\
\hline \multirow{4}{*}{ Total evaluation } & excellent & \\
\hline & good & \\
\hline & satisfactory & \\
\hline & sufficient & \\
\hline
\end{tabular}

Fig. 1 Standardised questionnaire of the DEGRO-academy

A further evaluation was initiated to find out which topics in the DEGRO-Curriculum were particularly overor underrepresented (Table 1). Aside from an increase in the total representation from 2018 to 2019, all the subtopics of the topics "01. Radiobiology", "02. Physics and radiation protection" and "06. Radiotherapy of benign diseases" were represented in certified courses.

Furthermore, there was a strong increase in the number of covered palliative medicine subtopics (36.7\% in 2018 to $76.7 \%$ in 2019). Particularly, certified courses in 2019 included more subtopics of "03. Radiation techniques", "04. Classification of acute and late reactions, supportive therapy", "07. Malignant oncological organ-related tumor entities, incl. radiochemotherapy and targeted drugs", and "08. Imaging in radiation oncology" than in 2018. By comparison, the topic "10. Other" which encompasses the subtopics "10.2. Prevention" and "10.3. Epidemiology, statistics and study planning" [4], indicated no significant change in representation between 2018 (27.3\%) and 2019 (36.4\%). The coverage of the topic "09. BVDST-relevant subjects, billing/DRG" decreased from $80.0 \%$ in 2018 to $46.7 \%$ in 2019.

\section{Evaluations}

In 2018 a total of 50 courses took place and 8 were evaluated with a total of 213 participants. 21 out of these 50 courses were refresher courses hosted by the DEGROAcademy at the annual meeting of the German Society 


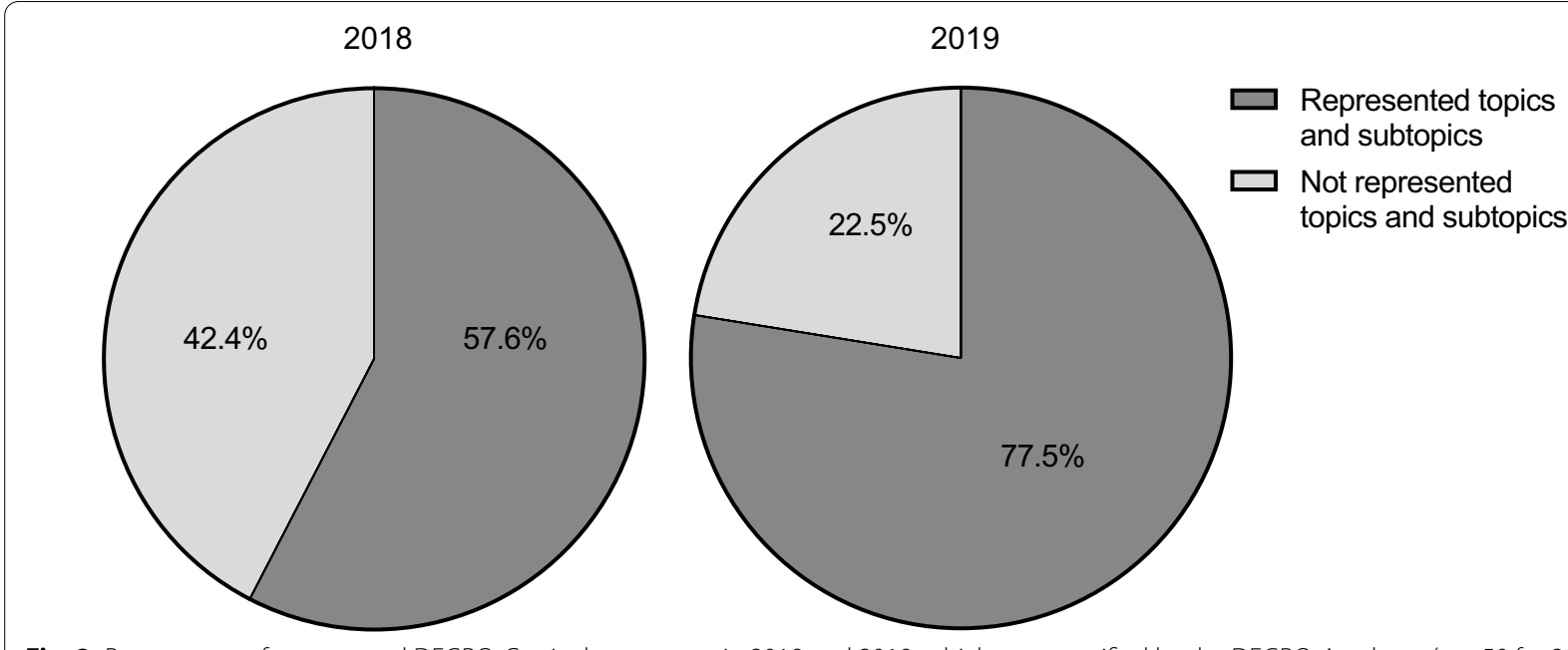

Fig. 2 Percentages of represented DEGRO-Curriculum courses in 2018 and 2019, which were certified by the DEGRO-Academy ( $n=50$ for 2018 ; $n=54$ for 2019)

Table 1 Curriculum topics of the DEGRO-Academy with number of respective subtopics (with a maximum of 2 subclassifications) and number of represented subtopics from the DEGRO-Curriculum in certified courses in 2018 and 2019 ( $n=50$ for 2018; $n=54$ for 2019)

\begin{tabular}{|c|c|c|c|c|c|}
\hline \multirow[t]{2}{*}{ Topics from the DEGRO-curriculum } & \multirow[t]{2}{*}{$\begin{array}{l}\text { Number of } \\
\text { subtopics }\end{array}$} & \multicolumn{4}{|c|}{$\begin{array}{l}\text { Number of represented subtopics in certified courses and } \\
\text { percentage of respective topic }\end{array}$} \\
\hline & & 2018 Number & $\%$ & 2019 Number & $\%$ \\
\hline 01. Radiobiology & 14 & 13 & 92.9 & 14 & 100.0 \\
\hline 02. Physics and radiation protection & 31 & 21 & 67.7 & 31 & 100.0 \\
\hline 03. Radiation techniques & 23 & 17 & 73.9 & 19 & 82.6 \\
\hline 04. Classification of acute and late reactions, supportive therapy & 22 & 11 & 50.0 & 17 & 77.3 \\
\hline 05. Palliative radiation oncology & 30 & 11 & 36.7 & 23 & 76.7 \\
\hline 06. Radiotherapy of benign diseases & 19 & 14 & 73.7 & 19 & 100.0 \\
\hline $\begin{array}{l}\text { 07. Malignant oncological organ-related tumor entities, incl. radio- } \\
\text { chemotherapy and targeted drugs }\end{array}$ & 74 & 35 & 47.3 & 56 & 75.7 \\
\hline 08. Imaging in radiation oncology & 22 & 10 & 45.5 & 17 & 77.3 \\
\hline 09. BVDST-relevant subjects, billing/DRG & 30 & 24 & 80.0 & 14 & 46.7 \\
\hline 10. Other & 11 & 3 & 27.3 & 4 & 36.4 \\
\hline Total & 276 & 159 & 57.6 & 214 & 77.5 \\
\hline
\end{tabular}

for Radiation Oncology. In 2019, a total of 54 courses including 23 refresher courses took place, 52 of them were evaluated and one was excluded from this study, due to unstandardized items in the questionnaire. The total number of participants was 1,565 . The exclusion was made on the basis of deviations in the questionnaire and a resulting lack of comparability to the remaining 51 courses. The score of each course was acquired by averaging the item "Total evaluation" from the participants of the respective course.

In 2018, the median score evaluated by 213 provided questionnaires from 8 courses was 1.62. In 2019 the evaluations of 1,565 questionnaires obtained a median scoring of 1.47 (Fig. 3). In both 2018 and 2019 none of the courses was scored with "sufficient". In summary, the scoring of the courses significantly improved between 2018 and 2019.

\section{Discussion}

As the global demands for improved patient care and medical infrastructure in the field of radiation oncology increase, the quality and intensity of its specialists education must adapt to increasing requirements [15, 16]. At the same time the adaptation of educational courses to increasing knowledge is needed but presents a challenge [17-20]. Three out of ten topics ("01. 


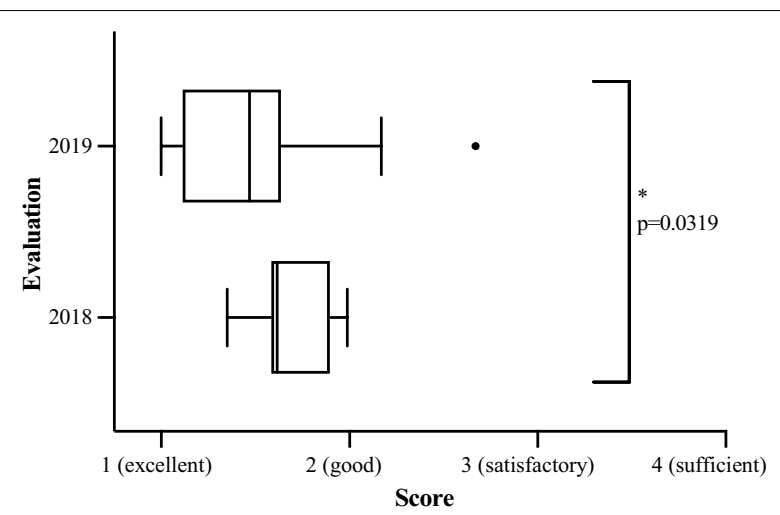

Fig. 3 Comparison of the scoring between 2018 and 2019 (2018: 8 evaluated courses with 213 participants; 2019: 51 evaluated courses with 1565 participants; median score 2018: 1.62, 2019: 1.47; $P$ value is significantly different with $p=0.0319$, Mann-Whitney $U$ test)

Radiobiology", "02. Physics and radiation protection" and "06. Radiotherapy of benign diseases") listed in the DEGRO-Curriculum are already completely covered by certified courses, amongst them the topic "02. Physics and radiation protection". In comparison to a different online survey addressed to specialists in training by Dietzel et al. [9], the item "Evaluation of knowledge levels regarding basic topics" rated "02. Physics and radiation protection" to be the worst scored, with more than $60 \%$ of the participants rating it with "mediocre" or "bad". The revision of course content and availability indicate a noticeable improvement in the area of residency training programmes and promises a better education for specialists. Furthermore, all subtopics of "01. Radiobiology" were represented in certified courses in 2019. A study in the US conducted by the American Society for Radiation Oncology (ASTRO) demonstrated in 2019 that, because of the importance of this area and the need for new graduate programmes focusing on radiobiology relating to radiation oncology, improved and advanced courses have to be developed [21].

Education in the field of palliative care is regarded as an important part of residency training programmes of radiation oncologists, since palliative medicine has a large impact on the daily working routine of physicians, as confirmed by Fels et al. [22] in 2019 analysing 205 eligible questionnaires. This was reflected by a substantial increase of certified courses covering this field between 2018 and 2019.

In addition, the coverage of "03. Radiation techniques" increased from 2018 to 2019. This topic encompasses modern techniques, such as stereotactic procedures and volumetric modulated radiotherapy (IMRT/VMAT), which have significantly increased [23-25]. A further component of this curriculum-topic is interventional radiotherapy, which has also become more accessible due to technical advancements, with an increasing number of brachytherapy treatments being recorded since 2004 [26, 27]. The need for an improvement of education in practical brachytherapy has also been reported in Italy, as shown in a recent study by Tagliaferri et al. [28] in 2019.

Other topics from the DEGRO-Curriculum such as "09. BVDST-relevant subjects, billing/DRG" and subtopics of "10. Other" require more certified courses in order to assure a broad education. Components of clinical research such as the subtopics "10.3. Epidemiology, statistics and study planning" and "10.5. Basics of evidencebased medicine" constitute part of this underrepresented area. An online survey by Krug et al. [29] of the yDEGRO showed that $70 \%$ of participants (260 survey respondents, $69 \%$ of them were medical doctors and the total median age was 33 years) had a particular interest in clinical versus preclinical/experimental (33\%) and physical/technical (36\%) research.

A European study by the ESTRO in 2020 concludes an urgent need for more support of innovative research by the national societies (58 national societies from 31 countries participated in this study) [30]. The need for more support was also documented by previous results from the Royal College of Radiology in 2012, where only $62 \%$ of the participants expressed their satisfaction with the degree of research education they gained during specialist training [31]. In Italy, this dissatisfaction was even more apparent after an evaluation with 197 participants (young radiation oncologists under the age of 40) conducted by Franco et al. in 2013. The authors report that most participants with high interest in clinical research (excellent/good: 70.6\%) were unable to gain experience in this area (moderate/poor: 68\%) [32]. A study by the Association of Residents in Radiation Oncology (ARRO) involving 135 radiation oncologists revealed that more than $50 \%$ of post-graduate year-5 radiation oncology residents had less than 6 months of research experience during their specialist training [33]. This international comparison underlines an urgent need to renew and improve several courses, particularly in of the subtopics "10.3. Epidemiology and statistics, study planning" and "10.5. Basics of evidence-based medicine" of "10. Other" (Table 1).

It may be deduced from the improvement of evaluation results from 2018 to 2019 that course participants do recognise and appreciate the course material and a higher quality of specialist training. Internationally, the importance of these certified courses and the associated CME is also recognised [30].

Another international comparison discussed large difficulties in the implementation of the ESTRO Core 
Curriculum on a nationwide scale. This year, a European study by Giuliani et al. [34] included 26 national societies from 26 different countries, reported complaints that governmental support is lacking in the implementation of the ESTRO Core Curriculum. Additionally, $44 \%$ of the participants were missing qualified staff members with professional teaching skills on the ESTRO Core Curriculum. In Germany, a similar observation was made in a study by Semrau et al. [2]. The authors came to the overall conclusion that out of 96 participants (members of the DEGRO and affiliated professionals), $60 \%$ suggested that there should be a stricter adherence to the training guidelines as laid out by the DEGRO-Curriculum, and 55\% of the participants answered that more involvement by the DEGRO would prove beneficial.

Currently, radiation oncology plays an integral, but underrepresented role in the clinical education of medical students in Germany [35]. A study in the US suggests a further approach with a standardised curriculum for 4-week clerkships by medical students in the field of radiation oncology [36]. Another study by the ESTRO reported that the most important item in the education of radiation oncology is practical training (77\% of participants) [37].

These findings indicate, that high quality education in the field of radiation oncology is extremely important to implement at an earlier stage of training in order to keep German radiation oncologists internationally competitive. The optimization of patient treatment requires the continued adjustment of the German healthcare system and the education of its specialists to increasingly high standards.

\begin{abstract}
Abbreviations
DEGRO-Academy: Academy of the German Society for Radiation Oncology; CME: Continuous Medical Education; DEGRO-Curriculum: The curriculum introduced by the Academy of the German Society for Radiation Oncology; yDEGRO: Young DEGRO; ESTRO: European Society for Radiotherapy and Oncology; ASTRO: American Society for Radiation Oncology; IMRT: Intensitymodulated radiotherapy; VMAT: Volumetric modulated radiotherapy; ARRO: Association of Residents in Radiation Oncology.
\end{abstract}

\section{Supplementary Information}

The online version contains supplementary material available at https://doi. org/10.1186/s13014-021-01785-7.

Additional file 1: Curriculum of the DEGRO-Academy, Version 2018.

\section{Acknowledgements}

None.

\section{Authors' contributions}

MB: conception, manuscript draft, increased intellectual content, literature research. NC conception, increased intellectual content, revision. TG conception, increased intellectual content, revision. DH conception, increased intellectual content, revision. GK conception, increased intellectual content, revision. OM conception, increased intellectual content, revision. MM conception, increased intellectual content, revision. JS conception, increased intellectual content, revision. ET conception, literature review, increased intellectual content, revision. $\mathrm{HC}$ conception, literature review, increased intellectual content, revision. MN conception, manuscript draft, literature review, increased intellectual content, revision. All authors read and approved the final manuscript.

\section{Funding \\ Open Access funding enabled and organized by Projekt DEAL.}

\section{Availability of supporting data}

Not applicable.

\section{Declarations}

Ethics approval and consent to participate

Not applicable.

\section{Consent for publication}

Not applicable.

\section{Competing interests}

The authors declare that there are no conflicts of interest.

\section{Author details}

${ }^{1}$ Department of Radiation Oncology, University Hospital, LMU Munich, Marchioninistraße 15, 81377 Munich, Germany. ${ }^{2}$ German Cancer Consortium (DKTK), Partner Site Munich, Munich, Germany. ${ }^{3}$ Department of Radiotherapy and Radiation Oncology, Faculty of Medicine and University Hospital Carl Gustav Carus, Technische Universität Dresden, Dresden, Germany. ${ }^{4}$ OncoRay-National Center for Radiation Research in Oncology, Faculty of Medicine and University Hospital Carl Gustav Carus, Technische Universität Dresden, Helmholtz-Zentrum Dresden-Rossendorf, Dresden, Germany. ${ }^{5}$ National Center for Tumor Diseases (NCT), Partner Site Dresden, Dresden, Germany. ${ }^{6}$ German Cancer Research Center (DKFZ), Heidelberg, Germany.

${ }^{7}$ Faculty of Medicine and University Hospital Carl Gustav Carus, Technische Universität Dresden, Dresden, Germany. ${ }^{8}$ Helmholtz Association/HelmholtzZentrum Dresden - Rossendorf (HZDR), Dresden, Germany. ${ }^{9}$ HelmholtzZentrum Dresden-Rossendorf, Institute of Radiooncology - OncoRay, Dresden, Germany. ${ }^{10}$ Department of Radiotherapy and Radio-Oncology, University Medical Center Hamburg-Eppendorf, Hamburg, Germany. ${ }^{11}$ Radprax MVZ, Leimbacher Str. 51a, 42281 Wuppertal, Germany. ${ }^{12}$ Clinic for Radiation Oncology, Chemnitz Medical Center, Chemnitz, Germany. ${ }^{13}$ Department of Radiotherapy and Radiation Oncology, Franziskus Hospital Bielefeld, Kiskerstrasse 26, 33615 Bielefeld, Germany. ${ }^{14}$ Department of Radiation Oncology, University Medical Center Jena, Jena, Germany. ${ }^{15}$ PRO RadioOncology GmbH, Poststraße 10-12, 27404 Zeven, Germany. ${ }^{16}$ Department of Radiation Oncology, Hannover Medical School, 30625 Hannover, Germany.

Received: 18 January 2021 Accepted: 10 March 2021

Published online: 20 March 2021

\section{References}

1. German Society of Radiation oncology (2004) DEGRO-Akademie. https:// www.degro.org/akademie/. Accessed 24 Aug 2020

2. Semrau R, Hansemann K, Adam M, Andratschke N, Brunner T, Heinzelmann $F$, et al. Quality of training in radiation oncology in Germany. Results of a 2006 survey. Strahlenther Onkol. 2008;184(5):239-44. https:// doi.org/10.1007/s00066-008-1821-7.

3. Loose R, Wucherer M. Certification guidelines and qualification courses. Radiologe. 2017;57(7):529-33. https://doi.org/10.1007/ s00117-017-0249-4.

4. German Society of Radiation oncology (2018) Curriculum zur Weiterbildung zum "Facharzt für Strahlentherapie". https://www.degro.org/akade mie/curriculum/. Accessed 24 Aug 2020 
5. Landesärztekammer Baden-Württemberg (2020) Weiterbildungsordnung der Landesärztekammer Baden-Württemberg vom 18. Mai 2020. https:// www.aerztekammer-bw.de/10aerzte/01 bekanntmachungen/wbo-2020. pdf. Accessed 24 Aug 2020

6. B Bayerische Landesärztekammer (2020) Qualifikationen nach der Weiterbildungsordnung: Facharzt für Strahlentherapie. https://www.blaek.de/ weiterbildung/qualifikationen-nach-der-weiterbildungsordnung/facha rzt-fuer-strahlentherapie. Accessed 24 Aug 2020

7. Bundesärztekammer (2009) Evaluation der Weiterbildung 2009. https:// www.bundesaerztekammer.de/aerzte/aus-weiter-fortbildung/weiterbild ung/evaluation-der-weiterbildung/ergebnisse-2009/. Accessed 29 Aug 2020

8. Bundesärztekammer (2011) Evaluation der Weiterbildung 2011. https:// www.bundesaerztekammer.de/aerzte/aus-weiter-fortbildung/weiterbild ung/evaluation-der-weiterbildung/ergebnisse-2011/. Accessed 29 Aug 2020

9. Dietzel CT, Jablonska K, Niyazi M, Gauer T, Ebert N, Ostheimer C, et al. Quality of training in radiation oncology in Germany: where do we stand? : Results from a 2016/2017 survey performed by the working group "young DEGRO" of the German society of radiation oncology (DEGRO). Strahlenther Onkol. 2018;194(4):293-302. https://doi.org/10. 1007/s00066-017-1250-6.

10. Käsmann L, Niyazi M, Blanck O, Baues C, Baumann R, Dobiasch S, et al. Predictive and prognostic value of tumor volume and its changes during radical radiotherapy of stage III non-small cell lung cancer : A systematic review. Strahlenther Onkol. 2018;194(2):79-90. https://doi.org/10.1007/ s00066-017-1221-y.

11. Bölling T, Seegenschmiedt H, Semrau R, Rödel C. Weiterbildung zum Facharzt für Strahlentherapie in Deutschland. Strahlenther Onkol. 2009;185(5):275-81. https://doi.org/10.1007/s00066-009-2003-y.

12. Leer JW, Overgaard J, Heeren G. The European core curriculum on radiotherapy. Radiother Oncol. 1991;22(3):153-5. https://doi.org/10.1016/ 0167-8140(91)90016-a.

13. Benstead K, Lara PC, Andreopoulos D, Bibault JE, Dix A, Eller YG, et al. Recommended ESTRO core curriculum for radiation oncology/radiotherapy 4th edition. Radiother Oncol. 2019;141:1-4. https://doi.org/10.1016/j. radonc.2019.08.013.

14. Röper B, Würschmidt F, Molls M. Remembering DEGRO 2000-evaluation of the refresher course survey. Strahlenther Onkol. 2001;177(7):375-7.

15. Datta NR, Samiei M, Bodis S. Radiotherapy infrastructure and human resources in Europe - present status and its implications for 2020. Eur J Cancer. 2014;50(15):2735-43. https://doi.org/10.1016/j.ejca.2014.06.012.

16. Smith BD, Haffty BG, Wilson LD, Smith GL, Patel AN, BuchholzTA. The future of radiation oncology in the United States from 2010 to 2020: will supply keep pace with demand? J Clin Oncol. 2010;28(35):5160-5. https://doi.org/10.1200/jco.2010.31.2520.

17. Krause M, Supiot S. Advances in radiotherapy special feature. Br J Radiol. 2015;88(1051):20150412. https://doi.org/10.1259/bjr.20150412.

18. Nakamura K, Sasaki T, Ohga S, Yoshitake T, Terashima K, Asai K, et al. Recent advances in radiation oncology: intensity-modulated radiotherapy, a clinical perspective. Int J Clin Oncol. 2014;19(4):564-9. https://doi. org/10.1007/s10147-014-0718-y.

19. Fietkau R, Budach W, Zamboglou N, Thiel HJ, Sack H, Popp W. Time management in radiation oncology: development and evaluation of a modular system based on the example of rectal cancer treatment. The DEGRO-QUIRO trial Strahlenther Onkol. 2012;188(1):5-11. https://doi.org/ 10.1007/s00066-011-0003-1.

20. Winkler C, Duma MN, Popp W, Sack H, Budach V, Molls M, et al. Protection of quality and innovation in radiation oncology: the prospective multicenter trial QUIRO of DEGRO: evaluation of time, attendance of medical staff, and resources during radiotherapy with tomotherapy. Strahlenther Onkol. 2014;190(10):950-6. https://doi.org/10.1007/s00066-014-0615-3.

21. Rosenstein BS, Held KD, Rockwell S, Williams JP, Zeman EM. American Society for Radiation Oncology (ASTRO) survey of radiation biology educators in U.S. and Canadian radiation oncology residency programs. Int J Radiat Oncol Biol Phys. 2009;75(3):896-905. https://doi.org/10.1016/j. ijrobp.2009.05.009.

22. Fels J, Pigorsch S, Vorwerk H, Engenhart-Cabillic R, van Oorschot B. Palliative care in everyday practice of radiation oncologists : Results from a web-based survey among medical members of the German Society for Radiation Oncology (DEGRO). Strahlenther Onkol. 2019;195(7):659-67. https://doi.org/10.1007/s00066-018-1403-2.

23. Guckenberger M, Baus WW, Blanck O, Combs SE, Debus J, EngenhartCabillic R, et al. Definition and quality requirements for stereotactic radiotherapy: consensus statement from the DEGRO/DGMP Working Group Stereotactic Radiotherapy and Radiosurgery. Strahlenther Onkol. 2020;196(5):417-20. https://doi.org/10.1007/s00066-020-01603-1.

24. Frenzel T, Krüll A. The use of IMRT in Germany. Strahlenther Onkol. 2015;191(11):821-6. https://doi.org/10.1007/s00066-015-0832-4.

25. Weber HE, Dröge LH, Hennies S, Herrmann MK, Gaedcke J, Wolff HA. Volumetric intensity-modulated arc therapy vs. 3-dimensional conformal radiotherapy for primary chemoradiotherapy of anal carcinoma. Strahlenther Onkol. 2015;191(11):827-34. https://doi.org/10.1007/s00066-015-0859-6.

26. Han K, Milosevic M, Fyles A, Pintilie M, Viswanathan AN. Trends in the utilization of brachytherapy in cervical cancer in the United States. Int J Radiat Oncol Biol Phys. 2013;87(1):111-9. https://doi.org/10.1016/j.jirobp. 2013.05.033.

27. Hoskin PJ, Bownes P. Innovative technologies in radiation therapy: brachytherapy. Semin Radiat Oncol. 2006;16(4):209-17. https://doi.org/ 10.1016/j.semradonc.2006.04.003.

28. Tagliaferri L, Kovács G, Aristei C, De Sanctis V, Barbera F, Morganti AG, et al. Current state of interventional radiotherapy (brachytherapy) education in Italy: results of the INTERACTS survey. J Contemp Brachyther. 2019;11(1):48-53. https://doi.org/10.5114/jcb.2019.83137.

29. Krug D, Baumann R, Rieckmann T, Fokas E, Gauer T, Niyazi M. Situation of young radiation oncologists, medical physicists and radiation biologists in German-speaking countries: Results from a web-based survey of the Young DEGRO working group. Strahlenther Onkol. 2016;192(8):507-15. https://doi.org/10.1007/s00066-016-1003-y.

30. Garibaldi C, Jornet N, Tee Tan L, Boejen A, Franco P, Bussink J, et al. National societies' needs as assessed by the ESTRO National Society Committee survey: a European perspective. Radiother Oncol. 2020. https:// doi.org/10.1016/j.radonc.2020.08.001.

31. Benstead K, Gilson D, Hanna L, Radhakrishna G, McAleer J, Bloomfield $D$, et al. Training in clinical oncology: results of the Royal College of Radiologists'survey of new consultants. Clin Oncol (R Coll Radiol). 2012;24(10):e143-8. https://doi.org/10.1016/j.clon.2012.08.005.

32. Franco P, Ciammella P, Peruzzo Cornetto A, De Bari B, Buglione M, Livi L, et al. The STYRO 2011 project: a survey on perceived quality of training among young Italian radiation oncologists. Med Oncol. 2013;30(4):729. https://doi.org/10.1007/s12032-013-0729-y.

33. Nabavizadeh N, Burt LM, Mancini BR, Morris ZS, Walker AJ, Miller SM, et al. Results of the 2013-2015 Association of Residents in Radiation Oncology Survey of Chief Residents in the United States. Int J Radiat Oncol Biol Phys. 2016;94(2):228-34. https://doi.org/10.1016/j.ijrobp.2015.10.014.

34. Giuliani M, Martimianakis MAT, Benstead K, Grau Eriksen J, Verfaillie C, Van Egten $V$, et al. Exploring implementation of the ESTRO Core Curriculum at the national level. Radiother Oncol. 2020;147:118-22. https://doi.org/10. 1016/j.radonc.2020.03.028.

35. Oertel M, Linde P, Mäurer M, Fleischmann DF, Dietzel CT, Krug D. Quality of teaching radiation oncology in Germany-where do we stand? : Results from a 2019 survey performed by the working group "young DEGRO" of the German Society of Radiation Oncology. Strahlenther Onkol. 2020;196(8):699-704. https://doi.org/10.1007/s00066-020-01623-x.

36. Golden DW, Spektor A, Rudra S, Ranck MC, Krishnan MS, Jimenez RB, et al. Radiation oncology medical student clerkship: implementation and evaluation of a bi-institutional pilot curriculum. Int J Radiat Oncol Biol Phys. 2014;88(1):45-50. https://doi.org/10.1016/j.jijobp.2013.10.041.

37. Bibault JE, Franco P, Borst GR, Van Elmpt W, Thorwhart D, Schmid MP, et al. Learning radiation oncology in Europe: Results of the ESTRO multidisciplinary survey. Clin Transl Radiat Oncol. 2018;9:61-7. https://doi.org/10. 1016/j.ctro.2018.02.001.

\section{Publisher's Note}

Springer Nature remains neutral with regard to jurisdictional claims in published maps and institutional affiliations. 